\title{
ALGUMAS RELAÇÕES ENTRE BEHAVIORISMO RADICAL E DETERMINISMO: UMA ANALISE DE PUBLICAÇÓES DE DIFERENTES AUTORES
}

\author{
RELATIONS BETWEEN RADICAL BEHAVIORISM AND DETERMINISM: A \\ PUBLICATION ANALYSIS OF DIFFERENT AUTHORS \\ Rodrigo Pinto Guimarães \\ UNIVERSIDADE SALVADOR E FACULDADE DE TECNOLOGIA E CIÊNCIAS, BRASIL \\ NilZa MichelETtO \\ PONTIFÍCIA UNIVERSIDADE CATÓLICA DE SÃO PAULO, BRASIL
}

\begin{abstract}
RESUMO
Esta pesquisa analisou artigos publicados em periódicos nacionais e estrangeiros entre 1972 e 2008 que abordam as relações entre Behaviorismo Radical e determinismo. As definições de determinismo e os tipos de relaçôes estabelecidas entre Behaviorismo Radical e determinismo foram analisadas. Mais publicações sobre o tema ocorreram a partir do fim da década de 80 até o início da década atual. As duas definiçóes mais comuns de determinismo encontradas foram as que definem determinismo em termos do modelo causal do mecanicismo e do modelo causal de seleção por conseqüências. Sete tipos diferentes de relações estabelecidas entre behaviorismo radical e determinismo foram identificadas; exceto a primeira relação todas as outras expressam algum tipo de posição determinista: 1) negação do determinismo; 2) afirmação do determinismo; 3) aproximação do mecanicismo; 4) afastamento do mecanicismo; 5) afastamento de modelos causais teleológicos; 6) aproximação de modelos que buscam em variáveis ambientais externas ao organismo as causas do comportamento e 7) alinhamento do behaviorismo radical com modelos de determinação que consideram diferentes níveis de determinação. Afastamento dos modelos mecanicistas foi a relação mais comum identificada nos artigos
\end{abstract}

Palavras-chave: Behaviorismo Radical, determinismo, Skinner

\begin{abstract}
This study analyzed articles that discuss the relationship between Radical Behaviorism and determinism published in national and international journals between 1972 and 2008. The definitions of determinism and the types of relations established between Radical Behaviorism and determinism were also analyzed. The results show that there was a high rate of publication from the end of the 80's to the beginning of this decade. The most common definitions of determinism found were those that defined determinism in terms of the causal modes of mechanism and of selection by consequences. Seven different types of relations between radical behaviorism and determinism were found: 1) denial of determinism; 2) assertion of determinism; 3) approximation to mechanistic modes; 4) dissociation from mechanistic modes; 5) dissociation from teleological causal modes; 6) approximation to causal modes that search for the causes of behavior in external environmental variables; 7) approximation to causal modes that consider different levels of determination. Dissociation from mechanistic models was the most common relation identified in the articles.
\end{abstract}

Keywords: Radical Behaviorism, determinism, Skinner

Skinner desenvolveu uma ciência do comportamento que encontrava no determinismo um dos seus postulados fundamentais. Supor que o comportamento não é um fenômeno determinado, no sentido de que é caprichoso, não faz sentido para uma ciência que tem na previsão e no controle do fenômeno comportamental um dos seus

\footnotetext{
Este trabalho é parte da dissertação de mestrado do primeiro autor, Uma Análise Histórica de Respostas Verbais de Relacionar Behaviorismo Radical e Determinismo, sob orientação da segunda autora, no Programa de Psicologia Experimental: Análise do Comportamento da PUC-SP. O primeiro autor recebeu auxilio da CAPES, em forma de bolsa de mestrado. Endereço para correspondência: Rua do Barro Vermelho, 299, Ed. Estrela do Mar, apt. 602, Rio Vermelho. Salvador - BA. Cep: 41940-340, e-mail: pguimaraes.rodrigo@gmail.com.
} 
objetivos (Skinner, 1953/1998) ${ }^{1}$. Nas palavras do próprio Skinner:

Para ser possível uma ciência do comportamento devemos adotar o postulado fundamental de que o comportamento humano é um dado ordenado [lawful] e que não pode ser perturbado [disturbed] pela ação caprichosa de qualquer agente livre [free agent] - em outras palavras, que ele é completamente determinado. (Skinner, 1947/1999, p. 345).

Afirmações como essa são bastante comuns ao longo dos trabalhos de Skinner (1947/1999; 1957/1992; 1974/1976; 1989). Em 1953, no livro Ciência e Comportamento Humano, Skinner novamente faz afirmaçôes sobre o determinismo, comportamento humano e o uso dos métodos da ciência para seu estudo:

Se vamos usar os métodos da ciência no campo dos assuntos humanos, devemos pressupor que o comportamento é ordenado e determinado. Devemos esperar descobrir que o que o homem faz é o resultado de condiçôes que podem ser especificadas e que, uma vez determinadas, poderemos antecipar e até certo ponto determinar as açōes. (Skinner, 1953/1998, p. 7)

Para Skinner, é necessário estudar as determinações do comportamento o que torna possível prevê-lo e controlá-lo.

Em About Behaviorism (1974/1976), Skinner elenca cerca de 20 críticas, segundo ele errôneas, ao Behaviorismo Radical ou à ciência do comportamento. Entre tais críticas, estão aquelas relacionadas com a determinação do comportamento humano:
Ignora consciência, sentimentos e estados mentais... Negligencia dons inatos e defende que todo o comportamento é adquirido durante o período de vida de um indivíduo... Formula o comportamento simplesmente como um conjunto de respostas a estímulos, representando, desta forma, uma pessoa como um autômato, robô, fantoche ou máquina... Não atribui qualquer papel ao eu ao à consciência do eu... Limita-se apenas à predição e ao controle do comportamento e desconsidera a natureza essencial do ser humano. (p. 4)

Diferentes trabalhos analisaram a noção de determinação presente no Behaviorismo Radical (Begelman, 1978; Day, 1969; Marr, 1982; Moxley, 1997; Vaughan Jr., 1983; Vorsteg, 1974). No conjunto desses trabalhos é possível identificar uma pluralidade de análises sobre a noção de determinismo presente no Behaviorismo Radical e, de forma marcante, há uma falta de consenso.

Segundo, Slife, Yanchar e Williams (1999), “... não há definição padrão de determinismo na literatura behaviorista radical." (p. 76). Apesar de o pensamento de Skinner, de maneira geral, ser caracterizado por vários autores como determinista, tal caracterização, mais do que consenso, tem gerado divergências e desentendimentos (Slife et al., 1999).

Determinismo tem sido uma suposição central em várias formas de behaviorismo, incluindo o Behaviorismo Radical. No entanto, esta suposiçāo tem sido um obstáculo para várias pessoas - tanto dentro como fora do campo do Behaviorismo Radical - resultando em equívocos e más interpretações. (p. 75)

\footnotetext{
${ }^{1}$ Sempre que houver duas datas, a primeira refere-se ao ano original da publicação e a segunda ao ano consultado.
} 
Compreender tais divergências e possíveis equívocos, numa perspectiva Behaviorista Radical, envolve identificar o comportamento verbal dos autores que se propóem a caracterizar o pensamento de Skinner. Diferentes autores parecem divergir na definição de determinismo, atribuindo ao termo diferentes significados (Begelman, 1978; Day, 1969; Marr, 1982; Moxley, 1997; Vaughan Jr., 1983; Vorsteg, 1974).

Segundo Skinner (1957/1992), "significado não é uma propriedade do comportamento como tal, mas das condiçôes sob as quais o comportamento ocorre" ( $p$. 13 e 14). Em outras palavras, afirmar que existem diferentes significados de determinismo na literatura Behaviorista Radical equivale a dizer que a resposta verbal, determinismo, emitida pelos diferentes autores, que se propóem a discutir o tema, é controlada por diferentes variáveis.

Segundo Skinner (1957/1992), ao produzir conhecimento sobre um determinado fenômeno, neste caso sobre as relações entre determinismo e Behaviorismo Radical, o cientista está, na verdade, emitindo comportamento verbal que poderá permitir futuros ouvintes, que podem ou não ser outros cientistas, se comportarem efetivamente em relação ao fenômeno em questão (p. 418).

Skinner (1957/1992) enfatiza a importância do controle preciso de estímulos sobre as respostas verbais dos cientistas, no sentido das mesmas variáveis controlarem a mesma resposta verbal. Esse controle preciso pode se dar pelo objeto de estudo ou por alguma de suas propriedades. Essa mesma precisão do controle de estímulos também se faz necessária quando as respostas verbais são sobre estímulos verbais.
A comunidade científica encoraja o controle preciso de estímulo sob o qual um objeto ou propriedade de um objeto é identificado ou caracterizado de tal modo que a ação prática será a mais efetiva... A comunidade lógica e científica também aguça e restringe comportamento verbal em resposta a estímulo verbal. Garantir a acurácia do comportamento ecóico e textual é um exemplo óbvio; é importante saber o que foi realmente dito, na forma vocal ou escrita. De maneira geral, contudo, práticas são planejadas para clarificar as relações entre uma resposta verbal para um estímulo verbal e as circunstâncias não verbais responsáveis por ela. (Skinner, 1957/ 1992, pp. 419 e 420)

Analisar o comportamento verbal dos cientistas, ou de qualquer outra pessoa, como afirma Skinner (1957/1992), gera conseqüências práticas importantes para a comunidade científica. A compreensão de variáveis controladoras da resposta verbal dos cientistas de caracterizar o Behaviorismo Radical como "determinista" pode favorecer o controle preciso do comportamento dos cientistas e suas decorrências práticas para comunidade científica.

Como exemplo de tais divergências e falta de consenso entre autores sobre as relações que podem ser estabelecidas entre Behaviorismo Radical e determinismo tem-se os trabalhos de Marr (1982) e Vaughan Jr. (1983). Ambos os autores apresentam respostas verbais topograficamente semelhantes, afirmando que o Behaviorismo Radical é determinista. No entanto, eles discordam entre si em relação às características do comportamento enquanto objeto de estudo, e às possibilidades e limites metodológicos do estudo do comportamento. Essa discordância entre eles indica que algumas das variáveis controladoras das respostas 
verbais de relacionar determinismo e Behaviorismo Radical, parecem ser diferentes.

Marr (1982) afirma que a posição adotada pelo Behaviorismo Radical requer uma perspectiva determinista, mas para este autor, comportamento ocorre espontaneamente. Em outras palavras, Marr (1982) supõe que a espontaneidade seja uma característica própria do comportamento, porém limitada pela genética da espécie e individual:

...espontaneidade pode ser uma característica típica do comportamento... Espontaneidade também não implica que simplesmente qualquer coisa possa ocorrer... a espécie a que se pertence e a dotação genética individual estabelecem limites naturais para a forma e variabilidade do comportamento espontaneamente emitido. (p. 206)

Vaughan Jr. (1983) também assume uma posição determinista, embora discorde de Marr (1982) sobre a espontaneidade do comportamento. O primeiro autor não admite a espontaneidade como característica do comportamento. Em seu artigo, Vaughan Jr. (1983) afirma que a espontaneidade do comportamento defendida por Marr (1982) é resultado de uma falta de evidências das variáveis controladoras, ou seja, é resultado de limitações metodológicas que impedem conhecimento e predição acurados sobre o comportamento:

No seu artigo "Determinismo", de 1982, Jackson Marr argumenta que o comportamento apresenta espontaneidade. Qual é a evidência comportamental para esta posição? É, e só pode ser, falta de evidência: casos... nos quais o comportamento muda, mas nós somos incapazes de especificar as variáveis controladoras... Nos casos em que Marr identifica como exibindo espontaneidade, nós podemos perguntar: um conhecimento maior sobre a história do organismo nos diria mais? Saber mais sobre o ambiente atual nos diria mais? Computadores mais potentes nos diriam mais?... Dizer que espontaneidade está presente no comportamento é o equivalente a dizer que nenhuma dessas operações nos permitiria fazer melhores predições sobre o comportamento. De onde tiramos licença para fazer tal inferência? (Vaughan Jr., 1983, p. 111)

Aproximadamente uma década depois, identifica-se a manutenção de algumas posições. Fraley (1994), assim como Vaughan Jr. (1983), também recusa a possibilidade de abandonar suposições deterministas em função de limites metodológicos. Segundo ele, a suposição determinista é oriunda da experiência científica e argumentos de cunho metodológico não a invalidam:

Limitações na capacidade de mensuração não
podem logicamente ser interpretadas como
ocasiões para abandonar suposições deterministas
sobre a natureza... O determinismo moderno dos
comportamentalistas e de outras ciências naturais
situa-se como uma grande indução de toda a
experiência científica... (p. 82)

Fraley (1994) argumenta ainda que quando predições precisas sobre um fenômeno não podem ser feitas, a ciência da probabilidade deve ser usada. No entanto, para Fraley, o uso da probabilidade não significa que o fenômeno sob investigação seja desordenado ou aleatório:

A incapacidade de descobrir todas as variáveis que participam do controle de uma resposta operante e 
a inabilidade de investigar e medir seus respectivos efeitos e contribuiçōes... não foi considerado como uma ocasião para abandonar as pressuposições da ciência natural, mas sim como uma ocasião para buscar os princípios de outra ciência para ajudar. A ciência da probabilidade permite a alguém responder efetivamente a situaçôes que não permitem predições precisas... (p. 81).

Tourinho (2003), assim como Fraley (1994), ressalta a impossibilidade de lidar com todas as variáveis das quais o comportamento é função. Em decorrência disso, Tourinho afirma que o analista do comportamento trabalha com a noção de determinismo probabilístico:

O reconhecimento da multideterminação do comportamento (mesmo quando permanecemos apenas no nível ontogenético) levará o analista do comportamento a trabalhar com um determinismo probabilístico. O que significa isso? Basicamente, que é impossível lidar com todas as variáveis das quais um comportamento é função e que quando lidamos com algumas daquelas variáveis podemos apenas aumentar ou reduzir a probabilidade de um comportamento, mas não determiná-lo de modo absoluto. (p. 38)

Além de análises sobre a relação entre determinismo e Behaviorismo Radical elaboradas por alguns autores, identificamse trabalhos em que os autores (Begelman, 1978; Scharif, 1982; Vorsteg, 1974) analisam as respostas verbais de Skinner de relacionar determinismo e Behaviorismo Radical. Em outras palavras, os autores analisaram o posicionamento que, segundo eles, Skinner assumiu sobre a discussão em questão. Essa maneira de abordar o tema possibilita, aos autores, mostrar concordância ou discordância em relação à posição assumida por Skinner.

Para Scharif (1982), Skinner assume uma posição determinista em relação ao comportamento, e o que caracterizaria esta afirmação seria a crença em uma relação necessária entre eventos. Ao falar na crença de uma correlação necessária entre eventos, Scharif diz:

...a única coisa que pode ter incitado essa opinião [de que correlações necessárias entre eventos podem ser observadas] é uma suposição ontológica subjacente e profundamente enraizada de que qualquer ciência... lida com um mundo de fenômenos necessariamente correlacionados. (p. 48)

Ainda segundo Scharif (1982), a suposição ontológica determinista de Skinner também não pode ser invalidada por limitações metodológicas:

Skinner sustenta que a razão pela qual sua ciência só pode prover explicações prováveis do comportamento não é porque o mundo é indeterminado, mas sim por causa de limitações do cientista... Essa limitação, insiste Skinner, não prova que o mundo é desordenado [unlawful]. Apenas ilustra as inadequações da ciência humana. (p. 53)

Vorsteg (1974) tem uma análise semelhante à de Scharif (1982). Para ele, a posição de Skinner em relação ao determinismo é de uma pressuposição da relação necessária entre comportamento e suas variáveis de controle.

Quando dizemos que um comportamento é determinado, isso significa que ele é uma instância de uma lei causal... Por lei causal, eu entendo 
uma afirmação verdadeira sobre efeito, que quando quer que condições do tipo F ocorram, condições do tipo G invariavelmente ocorrerão... Essa é a noção de determinismo que Skinner parece ter em mente quando ele insiste na necessidade do determinismo. (pp. 109-110)

Divergências sobre o posicionamento que Skinner assumiu ocorrem nas análises de diferentes autores. Diferentemente da posição defendida por Vorsteg (1974) e Scharif (1982) - de que Skinner defende uma correlação necessária entre todas as instâncias do comportamento e suas variáveis controladoras - Begelman (1978) afirma não ser claro se Skinner supunha uma relação necessária estrita, ou simplesmente uma ordenação [lawfulness] dos fenômenos. Segundo Begelman “... ainda é uma questão aberta se Skinner usava as palavras 'ordenado' e 'determinado' no sentido de uma necessidade causal estrita [relações de necessidade entre eventos], ou num sentido menos rigoroso, como explicação probabilística” (p. 14 e 15). Na verdade, Begelman afirma não ser claro o que Skinner pretendia dizer quando utilizava o termo determinismo:

Existem poucas referências específicas ao determinismo como tal nos escritos de Skinner. Ele falou mais sobre o que a ordenação [lawfulness] do comportamento significa para conceitos como liberdade e responsabilidade moral, do que sobre que tipo de determinista ele realmente é. Conseqüentemente, a natureza precisa da posição filosófica de Skinner em relação ao determinismo - se é que ele tem uma - é obscura. (p. 14)

Esta divergência de opinião entre Begelman (1978) e Vorsteg (1974) exposta acima, pode ser evidenciada pelo seguinte comentário de Begelman: "Vorsteg parece estar atribuindo posições deterministas para Skinner que são duvidosas que o último tivesse tido" (p. 15).

Vorsteg (1974) atribui a Skinner uma posição determinista que supõe uma relação necessária e invariável entre comportamento e suas variáveis de controle e elabora uma posição em relação à explicação do comportamento humano que apresenta como sendo discordante da posição, segundo ele, defendida por Skinner. Vorsteg defende que a teoria do reforçamento operante não demonstra tal suposição (relação necessária entre eventos), pois as explicações do comportamento humano, baseadas nesta teoria, são de cunho probabilístico e não de cunho causal (relações necessárias e invariáveis). Para este autor, explicações probabilísticas não são necessariamente deterministas e, por essa razão, as explicações de Skinner, no tocante ao comportamento operante, não requerem a suposição do determinismo, nem mostram que tal suposição é verdadeira. Segundo Vorsteg:

\begin{abstract}
No caso do condicionamento operante, deve ser admitido que essas explicações [explicações baseadas no condicionamento operante] se aplicam às ações humanas. Mas também deve ser notado que elas não são explicações deterministas. Elas são explicações probabilísticas e não envolvem nenhuma lei causal. (p. 117).
\end{abstract}

Moxley (1997), assim como Vorsteg (1974), nega o determinismo no Behaviorismo Radical. Moxley, ao falar sobre as relações do determinismo com o Behaviorismo Radical, afirma que a consideração de Skinner como determinista precisa ser modificada. $\mathrm{Na}$ verdade, segundo este autor, a suposição do 
determinismo pareceu ser a única solução em um período histórico onde era necessário escolher "entre um mundo ordenado e determinado e um mundo caótico do acaso... A questão que surge é se o determinismo é a melhor explicação hoje” (p. 4).

Moxley (1997) opõe determinismo à visão selecionista, defende que o modelo de seleção pelas conseqüências não é um modelo de determinação. Neste sentido, opor o modelo de seleção por conseqüências ao determinismo parece ser, na verdade, uma oposição entre o modelo de seleção por conseqüências e o modelo mecanicista de determinação. "A receptividade original de Skinner [ao determinismo] é evidente a partir do seu conhecimento educacional e religioso e da aceitação difundida do determinismo mecanicista pela comunidade científica no começo da sua carreira.” (p. 14)

Para Marr (1982), diferentemente de Moxley (1997), abandonar noções mecânicas de causalidade não significa abandonar o determinismo.

Como analistas do comportamento nós somos imbuídos com uma perspectiva determinista... $\mathrm{O}$ abandono do determinismo mecanicista não deve ser visto com desespero pelos comportamentalistas, mas preferivelmente visto como libertação (assim como foi para a Física). (Marr, 1982, p. 205 e 207)

Chiesa (1994) também parece supor que o abandono do mecanicismo não significa a recusa do determinismo. Ao analisar modelos psicológicos de determinação do comportamento, a autora aponta para o fato de que modelos que não consideram o comportamento como objeto de estudo em si mesmo, mas sim expressão de algum outro fenômeno (entidades mentais, processos neurológicos ou fisiológicos, entre outros), podem ser considerados mecanicistas, pois requerem ligações seqüenciais e lineares entre tais fenômenos e o comportamento. Para Chiesa, o modelo causal de seleção pelas conseqüências do Behaviorismo Radical, proposto por Skinner de forma mais sistematizada em 1981, é incompatível com um modelo mecanicista de causalidade:

O modelo causal do Behaviorismo Radical [seleção pelas conseqüências] o separa da maioria da psicologia experimental contemporânea, pois ele não requer ligaçôes em uma cadeia causal para explicar as relações do seu objeto de estudo. (Chiesa, 1994, p. 96)

Uma variedade de respostas verbais de relacionar determinismo e Behaviorismo Radical pôde ser identificada nos trechos dos autores acima citados. Em alguns destes trechos é possível identificar afirmações que negam uma relação entre a proposta Behaviorista Radical e posições determinista (Moxley, 1997; Vorsteg, 1974). Em outros trechos, identificam-se afirmaçõos que defendem uma relação entre posições determinista e Behaviorismo Radical (Fraley, 1994; Tourinho, 2003; Vaughan Jr., 1983), mesmo que problemas de cunho metodológico dificultem o conhecimento de todas as variáveis de controle, impedindo, conseqüentemente, uma determinação e previsão exatas do comportamento humano. Há ainda outras respostas verbais (Marr, 1982; Moxley, 1997) em que se identifica o abandono de noções mecanicistas de causalidade. Dentre este último conjunto de respostas verbais, algumas defendem o abandono da perspectiva 
determinista como uma forma de abandonar o mecanicismo (Moxley, 1997), outras sugerem que o abandono da perspectiva mecanicista não requer $\mathrm{o}$ abandono da perspectiva determinista (Marr, 1982).

Neste contexto, foi objetivo do presente trabalho analisar artigos que abordam as relações entre Behaviorismo Radical e determinismo, publicados entre 1972 e 2008 em periódicos nacionais e internacionais e na coleção Sobre Comportamento e Cognição. Para isto, foram identificadas e caracterizadas respostas verbais de definir determinismo e de relacionar Behaviorismo Radical e determinismo. Tal caracterização pode ajudar a aumentar a "acurácia do comportamento ecóico e textual" da comunidade científica (Skinner, 1957/ 1992), na medida em que pode esclarecer o que está sendo dito pelos autores ao estabelecer estas relaçôes e colaborar para esclarecer discordâncias e equívocos presentes na comunidade científica sobre esta relação, favorecendo a produção de condições precisas de controle do comportamento dos cientistas.

\section{MÉTodo}

\section{Seleção das Fontes}

Artigos em língua estrangeira. Através do portal on-line - www.periodicos.capes.gov.br, foram consultadas duas bases de dados. A primeira base de dados é da Psicologia PsycINFO - e a segunda base de dados é da filosofia - Philosopher's Index. Ambos procuram as palavras de busca, utilizadas pelo pesquisador, nos títulos, resumos, palavraschaves, nomes de autores e referências dos trabalhos indexados em seus arquivos. Nessa busca foram localizados artigos em 17 fontes diferentes: 1) American Psychologist; 2)
Behavior and Philosophy; 3) Bulletin de Psychologie; 4) Educational Technology; 5) Journal of Applied Behavior Analysis; 6) Journal of the Experimental Analysis of Behavior; 7) Journal of the Experimental Child Psychology; 8) Nebraska Symposium on Motivation; 9) New Ideas in Psychology; 10) Psychological Reports; 11) Revista General y Aplicada; 12) Revista Latino Americana de Psicologia; 13) Southern Journal of Philosophy; 14) Teachers College Record; 15) The Behavior Analyst; 16) The Journal of Mind and Behavior; 17) The Psychological Record.

Artigos nacionais. Foram selecionados oito periódicos nacionais; três periódicos voltados a divulgar artigos de Análise do Comportamento: Cadernos de Análise de Comportamento, Revista Brasileira de Terapia Comportamental e Cognitiva (REBTCC), Revista Brasileira de Análise do Comportamento (ReBAC); quatro periódicos gerais em psicologia: Psicologia: Teoria e Pesquisa, Psicologia, Psicologia USP, Temas em Psicologia e um periódico geral para todas as áreas de conhecimento: Ciência e Cultura. Estes periódicos foram selecionados, pois são os mais importantes na veiculação de trabalhos de analistas do comportamento. Entre os periódicos não especializados, foram selecionados, os que mais publicam textos de analistas do comportamento. Cabe, entretanto, destacar que a produção de analistas do comportamento não se restringe a estes periódicos.

Além desses periódicos, foi incluída a coleção Sobre Comportamento e Cognição, por ser de domínio público que, em tais fontes, há uma grande concentração de publicações de analistas do comportamento brasileiros. 
Todos os periódicos foram consultados a partir do seu ano inicial de publicação, com exceção do periódico Ciência e Cultura. Esse periódico foi consultado a partir do ano de 1961, data em que Keller veio pela primeira vez ao Brasil; é o marco de origem da abordagem da análise do comportamento no país, apontado por vários textos que analisam sua história no Brasil (Matos, 1996; Bori, 2001). Os últimos volumes e números consultados foram referentes ao ano de 2008 para os periódicos ainda em circulação (exceto os casos em que houve atrasos na publicação dos periódicos), ou o último número publicado para periódicos que já saíram de circulação.

\section{Seleção das Palavras de Busca}

A partir dos resumos, títulos e palavraschaves dos textos utilizados na Introdução deste trabalho, foram selecionadas palavras relacionadas com o respectivo tema, totalizando uma lista com 24 palavras de busca (todas em inglês, pois os bancos de dados só aceitam palavras em inglês). Destas 24 palavras listadas, seis foram consideradas palavras de busca básicas. Foram realizados, então, cruzamentos e combinaçôes entre as palavras da lista (132 combinaçôes). As palavras chaves básicas estão presentes em todas as combinações e não combinam entre si. A
Tabela 1 apresenta as 24 palavras de busca (em negrito as palavras chaves básicas).

\section{Seleção de Artigos}

Artigos em língua estrangeira. As duas bases de dados foram consultadas usando as combinações de palavras chaves. A partir da leitura dos títulos e resumos de todos os artigos localizados, foram excluídos aqueles nos quais não foram identificadas respostas verbais de relacionar determinismo e Behaviorismo Radical. Um total de 63 artigos foi selecionado e analisado.

Artigos nacionais. $\mathrm{O}$ critério de seleção foi similar ao utilizado para os bancos de dados. Todos os títulos, resumos (quando disponíveis) e palavras chaves de todos os artigos destes periódicos foram lidos com o intuito de identificar alguma das combinações de palavras de busca utilizadas anteriormente. Assim como os periódicos, os 21 primeiros volumes do livro Sobre Comportamento e Cognição também foram consultados. Como alguns volumes desta coleção não possuem resumo foi lido o primeiro parágrafo de cada texto no lugar do resumo. Após este procedimento de coleta de textos nacionais, foram encontrados 26 artigos.

\section{Tabela 1}

Palavras chaves de busca.

\begin{tabular}{|c|c|c|c|c|c|}
\hline Behaviorism & Radical & Behavior & B. F. Skinner & Skinner & Operant \\
\hline & Behaviorism & Analysis & & & Reinforcement \\
\hline Cause & Causation & Causality & Determinism & Selectionism & $\begin{array}{l}\text { Theory } \\
\text { probability }\end{array}$ \\
\hline $\begin{array}{l}\text { Functional } \\
\text { Relation }\end{array}$ & Mechanicism & Mechanism & Mechanistic & $\begin{array}{c}\text { Self } \\
\text { determination }\end{array}$ & $\begin{array}{l}\text { Environmental } \\
\text { determination }\end{array}$ \\
\hline $\begin{array}{l}\text { Selection by } \\
\text { Consequences }\end{array}$ & $\begin{array}{l}\text { Random } \\
\text { variation }\end{array}$ & $\begin{array}{l}\text { Necessitarian } \\
\text { causality }\end{array}$ & $\begin{array}{l}\text { Probabilistic } \\
\text { causality }\end{array}$ & Determination & $\begin{array}{l}\text { Probabilistic } \\
\text { determinism }\end{array}$ \\
\hline
\end{tabular}




\section{Registro das Informaçōes}

Um banco de dados foi criado, utilizando o programa Access, para registrar as seguintes informaçôes coletadas: ${ }^{2}$

1) Identificação do texto, por meio do título, autoria, ano de publicação, periódico, volume, página inicial e final;

2) Definições de determinismo - trechos em que foram localizadas respostas verbais dos autores de definir determinismo (caso ocorresse) foram transcritos no banco de dados. Após a transcrição, as definições foram agrupadas, de acordo com suas características, em cinco grupos diferentes. Algumas definições apresentam características de mais de um grupo, por isso podiam ser classificadas mais de uma vez. Os cinco grupos de definições foram: a) Relação funcional; b) Seleção por conseqüências; c) Mecanicismo; d) Determinismo metodológico e e) 'Outros'. Os critérios de inclusão e características de cada grupo de definiçóes encontram-se expostos na parte de resultados

3) Relação entre Behaviorismo Radical e determinismo - a) trechos dos artigos em que foram localizadas respostas verbais dos autores de relacionar determinismo e Behaviorismo Radical, e/ou b) trechos em que os autores analisam as respostas verbais de Skinner de relacionar determinismo e Behaviorismo Radical foram transcritos no banco de dados. Ao transcrever tais relaçôes, elas foram agrupadas em sete tipos diferentes: a) negação do determinismo; b) afirmação do determinismo; c) proximidade de modelos causais mecânicos; d) afastamento de modelos causais mecânicos; e) afastamento de modelos causais teleológicos ou finalistas; $\mathrm{f}$ ) causas externas $\mathrm{x}$ causas internas; g) proximidade de modelos causais que salientam diferentes níveis de determinação.

\section{Resultados e Discussāo}

Foram identificados 89 artigos em que os autores analisam as relaçóes entre determinismo e Behaviorismo Radical. Estas publicaçōes se distribuem ao longo de 36 anos; a primeira publicação detectada sobre o tema ocorreu em 1972 e a última em 2008.

Na Figura 1 está representado o número acumulado de artigos no período de 1972 a 2008. Os anos em que Skinner publicou livros e o artigo Seleção por conseqüências (1981/ 1987) - neste artigo Skinner apresenta de forma clara e sistematizada sua nova noção de causalidade - são indicados na figura, buscando analisar se alguma relação poderia ser estabelecida entre o aumento de freqüência de artigos e as publicações de Skinner. Durante este período, houve um crescimento, ao longo dos anos do número de artigos publicados sobre o tema, sendo que entre 1988 até 2001 houve um crescimento bastante acelerado das publicações. Durante este período foram publicados 62 dos 89 artigos coletados. Outro crescimento acelerado pode ser observado no período entre 2005 e 2008. Neste relativo curto período de tempo houve 12 publicações sobre o tema, indicando que tal discussão está atual na comunidade de analistas do comportamento.

Em 1971 foi publicado o livro Beyond Freedom and Dignity. O início, localizado neste trabalho, das publicações sobre o tema, em 1972, pode ter sido influenciado pelo livro. Depois de 1974 pode-se observar um aumento de publicações nos anos seguintes sobre o tema

2 As informações referentes à identificação dos textos, definições de determinismo e relaçóes estabelecidas entre Behaviorismo Radical e determinismo, para cada texto, estão disponíveis para consulta de pesquisadores no Centro de Referências do Behaviorismo Radical do Laboratório de Psicologia Experimental da PUC-SP. 


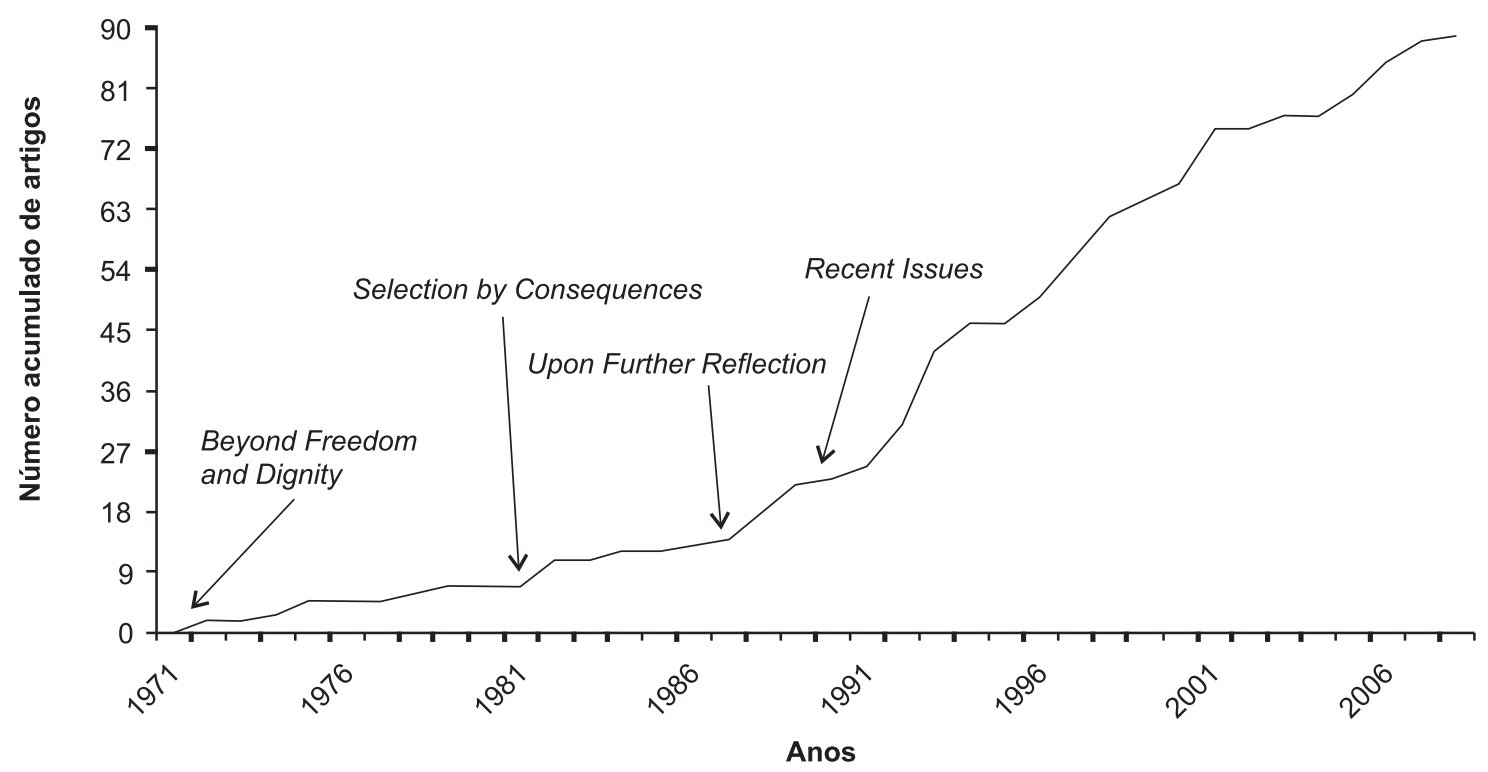

Figura 1. Número acumulado de artigos que relacionam Behaviorismo Radical e determinismo por ano.

que estagnaram entre 1979 e 1982. A partir de 1982, houve uma aceleração na curva, provavelmente influenciada pela publicação do artigo Selection by Consequences, em 1981. A partir de 1988 até 2001 observa-se um grande aumento nas publicações sobre o tema que pode estar relacionada com as publicações de Upon Further Reflection em 1987 e Recent Issues in the Analysis of Behavior em 1989.

Nos textos analisados diversas concepções de determinismo foram encontradas. Elas podem estar relacionadas às diferentes, e muitas vezes divergentes, relações estabelecidas entre determinismo e Behaviorismo Radical.

Dentre os 89 textos que apresentam respostas verbais de relacionar o Behaviorismo Radical e determinismo, 55 apresentam definiçôes de determinismo. Essas definiçôes de determinismo foram classificadas em cinco grupos de acordo com suas características.

$\mathrm{O}$ primeiro grupo se refere a definições que identificam determinismo como relação funcional. Constituem as características principais deste grupo: a) negação do modelo causal mecanicista baseado em forças que 'causariam' o comportamento através de uma ação temporal contígua, linear e unidirecional e b) afirmação da multideterminação do comportamento e ênfase na descrição de relações funcionais recíprocas e biunívocas entre eventos. Foram identificadas, em alguns textos, respostas verbais de definir determinismo que apresentavam características de mais de um grupo.

A seguinte definição de determinismo extraída do texto de Chiesa (1992) ilustra este primeiro grupo. "Hoje a concepção científica de causação refere-se a eventos que ocorrem 'como função' de outros eventos e não em termos de 'A exerce uma força em B'.' (p.1289)

O segundo grupo consiste de definições que identificam determinismo com o modelo de seleção por conseqüências. Este segundo grupo, assim como o primeiro, também se opõe a um modelo de causalidade mecânica e enfatiza a multideterminação do comportamento. Variação, seleção e inter-relação de diferentes níveis de determinação (filogenético, 
ontogenético e cultural) do fenômeno comportamental são características fundamentais destas definições. Abaixo um exemplo de definição pertencente a este grupo:

A seleção por conseqüências como um novo modelo que permite compreender a determinação do comportamento... envolve ambientes selecionadores e um organismo que age. A determinação do ambiente não é mecânica, e o organismo que age não é o iniciador... A seleção por conseqüências como um modelo causal destaca o caráter processual e histórico do comportamento, um processo com longas e diferentes extensões temporais, - da espécie, da vida do indivíduo e das práticas culturais - que envolve uma análise histórica integrada dos três níveis em que a seleção opera sobre o comportamento, tornando-o um objeto que se transforma como fruto de várias determinaçôes ambientais inter-relacionadas... Ação, variação e seleção e, conseqüentemente, transformaçôes são constitutivas dessa noção de determinação. (Micheletto, 1997, pp. 116, 120, 126, 127)

O terceiro grupo de definições se refere a concepções mecânicas de determinismo, ou seja, concepções que se baseiam na ação de forças invariáveis e necessárias que atuariam de forma unidirecional, linear e contiguamente no fenômeno em questão. O reflexo é um exemplo, apresentado em alguns dos textos que compõem este grupo, desta relação invariável de necessidade, no qual uma força (estímulo eliciador) desencadearia a ação (resposta reflexa), pois a despeito de outras condições, sem o estímulo eliciador não há resposta. Negação de forças ocultas sobrenaturais que determinam $o$ comportamento, afirmação de uma realidade imutável independente do sujeito que se comporta e critério de verdade do conhecimento como correspondência ao objeto constituem características encontradas neste grupo de definições. Exemplo na definição abaixo:

De acordo com a visão de mundo mecanicista... na causação os elementos são entendidos como agindo um sobre o outro como fazem as forças físicas. Os resultados são conexões tipo 'corrente' [chain-like connection] ou seqüências entre estímulos e respostas. Causação flui do estímulo para a resposta de uma maneira que é imediata, contígua e eficiente. O critério de verdade destes mecanismos causais é a correspondência: dado que conhecimento no mecanicismo é conhecimento sobre a natureza de uma ontologia realista, a verdade deste conhecimento é descoberta nas correspondências entre propriedades da atividade da máquina ou em previsões entre o que é dito sobre máquinas (ex. hipóteses) e como essas máquinas operam (ex. confirmações). (Morris, 1988, p. 299)

O quarto grupo refere-se a definições de determinismo que negam ou rejeitam qualquer tipo de afirmativa sobre a realidade, inexistindo, desta forma, qualquer afirmação sobre a natureza do objeto de estudo. Para este grupo de definições a aplicação do método científico permite "descobrir" regularidades no comportamento, mas isso é diferente de afirmar que o comportamento seja um fenômeno determinado, já que neste grupo de definições não há afirmações sobre a natureza do objeto de estudo. Este grupo foi chamado, neste trabalho, de "determinismo metodológico" (termo originalmente utilizado por Baldwin, 1988). Segue trecho abaixo do texto de Slife, et al. (1999) que ilustra este grupo de definiçóes de determinismo. 
Deterministas científicos distinguem os resultados dos seus métodos de afirmações metafísicas sobre a realidade. Eles acreditam que o mundo é melhor estudado através da aplicação cuidadosa do método científico. Previsão exata pode ser resultado deste estudo sistemático, na medida em que tendências históricas são usadas para antecipar respostas ainda não evocadas de um organismo. Entretanto, essas pressuposiçōes (ex. previsibilidade) são puramente metodológicas para um determinista científico; elas são inerentes ao método científico e ao seu uso, e não precisam ser estendidas para a realidade por si mesma. (p. 85)

O quinto e último grupo foi classificado como "outros", composto por definições com características diversas. Referência a modelos causais teleológicos e afirmação do comportamento como objeto de estudo próprio são exemplos de características das definições deste grupo. Veja exemplo abaixo.
Determinismo é uma suposição ontológica quando se refere à natureza das relaçôes de causa e efeito e é uma suposição epistemológica quando se refere à explicação. Epistemologicamente é uma negação da causalidade finalista e do acaso [final and chance causality], mas ela não requer uma negação dos antecedentes não materiais assumidos no mecanicismo teleológico e em versōes do "idealismo objetivo"... (Reese, 1993, pp. 68, 69)

$\mathrm{Na}$ Figura 2, é apresentado o número acumulado de artigos, em que foram identificadas respostas verbais de definir determinismo por grupo classificatório, através dos anos.

Respostas verbais de definir determinismo como "mecanicismo", como "seleção por conseqüências" e relação funcional foram as mais encontradas: 25, 21 e 14 respostas verbais, respectivamente. Desde os primeiros anos analisados, definir determinismo como mecanicismo foi a resposta verbal mais

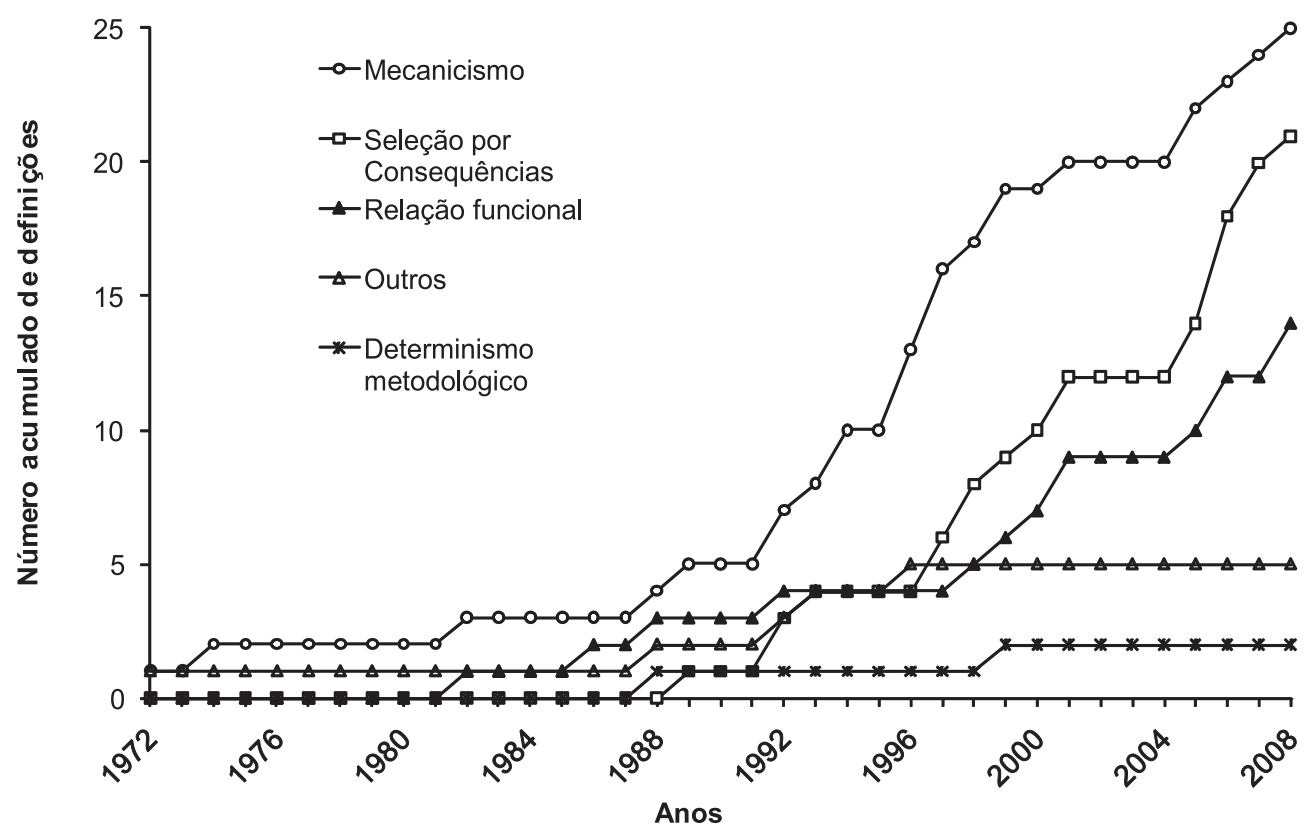

Figura 2. Número acumulado de definiçôes de determinismo por grupo classificatório através dos anos. 
freqüente. A primeira vez que foi identificada a resposta verbal de definir determinismo como seleção por consequiências ocorre em 1981, momento em que é publicado o artigo de Skinner "Seleção por Conseqüências". Observase uma maior aceleração no número acumulado de ambas as respostas verbais a partir de 1991 (ver Figura 2), um ano após a morte de Skinner. A resposta verbal de definir determinismo como mecanicismo é identificada sistematicamente entre 1991 e 1999 e entre 2005 e 2008; a de definir como seleção por consequiências destacase entre 1996 e 2001 e entre 2005 e 2008.

A grande maioria dos artigos analisados, 77 (cerca de $86 \%$ dos artigos), estabelece algum tipo de relação entre Behaviorismo Radical e determinismo, enquanto que apenas 12 (cerca de $14 \%$ dos artigos) artigos afirmam explicitamente que a posição Behaviorista Radical não é determinista.

No total, foram identificados sete grupos de respostas verbais de estabelecer relações entre Behaviorismo Radical e determinismo. Assim como para as respostas verbais de definir determinismo, um único texto pode apresentar mais de uma relação e ser contabilizado mais de uma vez. Portanto, a soma da quantidade de respostas verbais que estabelecem relações entre Behaviorismo Radical e determinismo ultrapassa o número total de artigos (89).

A Figura 3 apresenta, em dois painéis, o número acumulado de artigos por tipo de resposta verbal de relacionar Behaviorismo Radical e determinismo através dos anos. É a partir de 1974, ano de publicação de About Behaviorism, que são identificadas estas relações. Foram identificadas, nos anos iniciais, respostas verbais de afirmar o Behaviorismo Radical como um sistema determinista ( 15 artigos) e respostas verbais que atribuem a variáveis externas ao organismo fatores de determinação, como pode ser observado em ambos os painéis da Figura 3.

A partir de 1991, há um aumento no número de artigos nos quais foram localizadas respostas verbais que afastam modelos mecânicos de determinação do Behaviorismo Radical, tipo de resposta verbal que foi mais identificada, 41 artigos.

Em 21 artigos, respostas verbais de identificar o Behaviorismo Radical com um modelo que considera diferentes níveis de determinação (filo, onto e cultural) foram identificadas. É possível observar que há uma aceleração, para este grupo, no período entre 2005 e 2008. Foram publicados neste período quase $40 \%$ dos artigos deste grupo (oito artigos).

Uma das relações identificadas refere-se à negação do Behaviorismo Radical como perspectiva determinista de compreensão do comportamento humano (12 textos), especialmente entre 1996 e 1999. Os autores dos artigos pertencentes a este grupo afirmam literalmente que o Behaviorismo Radical não é uma filosofia determinista. O ponto central desta discussão gira em torno da impossibilidade de uma predição total do comportamento e da sua natureza probabilística de emissão devido à interação das inúmeras variáveis que participam da determinação do comportamento.

As respostas verbais que afastam o Behaviorismo Radical do determinismo em muitos textos estão relacionadas a afirmações que destacam a 'variação randômica/acaso' do fenômeno comportamental. Tais afirmações referem-se a uma desordem ou inconstância intrínseca do fenômeno sob estudo, o que impede sua explicação e previsão. Assim como nas mutações, não se sabe a origem da emissão da primeira resposta operante, sendo sua 
emissão tida como aleatória ou ao acaso. O conjunto de textos que aborda este tema, ao falar de determinismo discute o papel do acaso ou variação randômica como base fundacional do comportamento operante. Em outras palavras, processos randômicos controlariam a emissão de respostas operantes e isso contradiria, para estes autores, o determinismo.

Além disso, 8 dos 12 artigos ao abordarem esta relação de afastamento do determinismo destacaram o tema da seleção por conseqüências/ seleção natural, ou seja, referiram-se a um
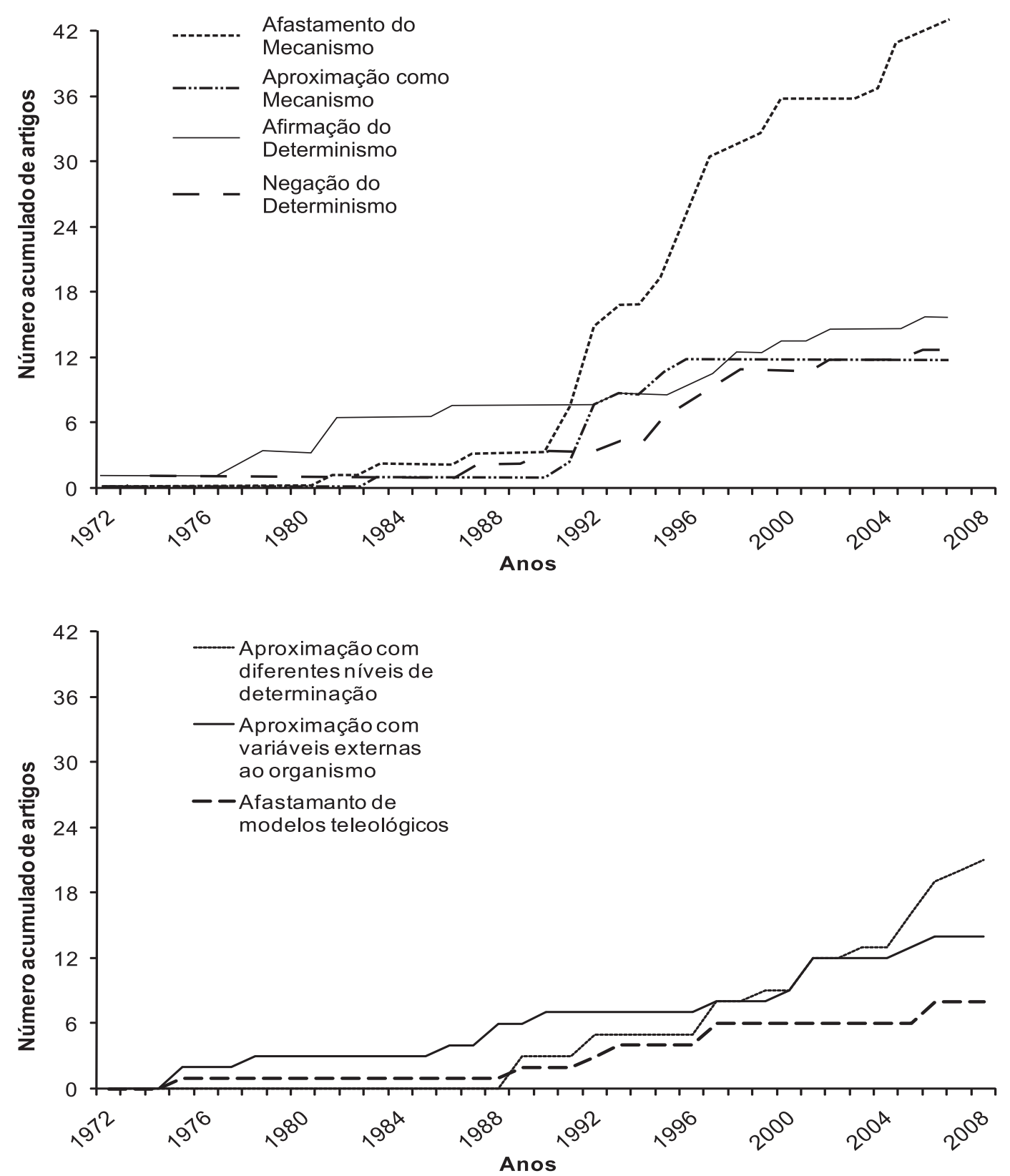

Figura 3. Número acumulado de artigos por tipo de relação estabelecida entre Behaviorismo Radical e determinismo através dos anos. 
modelo causal com duas características básicas: variação e seleção.

Respostas verbais que "afastam o Behaviorismo Radical do determinismo" (8 dos 12 textos) referem-se ao caráter probabilístico da unidade de medida da Análise do Comportamento (probabilidade de respostas) e das previsões comportamentais, em oposição a afirmaçóes de certeza absolutas ou previsões absolutas. Alguns destes textos também discutem o caráter probabilístico da unidade de análise acima mencionada como uma oposição a qualquer afirmação determinista sobre o comportamento. Em outras palavras, para os autores destes textos, o fato da Análise do Comportamento fazer afirmações e previsões apenas de ordem probabilística sobre o comportamento humano invalidaria qualquer tipo de afirmação de certeza absoluta (determinismo), visto que a certeza absoluta ou previsão total não possui um caráter probabilístico.

A análise deste conjunto de textos que apresentam respostas verbais de afastar Behaviorismo Radical de determinismo também revelou que, embora presente desde a década de 70, mais da metade dos artigos se concentra no período de 1994 a 1999. Além disso, dentre os 12 artigos deste conjunto, oito foram de autoria de um único autor (Roy A. Moxley), enquanto que o restante apresentou diferentes autores. Sete artigos de Roy A. Moxley foram publicados entre 1996 e 2003 e o último em 2007. Desconsiderando os textos do referido autor, o texto mais recente deste conjunto é datado de 1994. Desta forma, a afirmação de que o Behaviorismo Radical não é determinista parece não ter ocorrido nos últimos anos na comunidade de analistas do comportamento.
Outra relação estabelecida refere-se à 'afirmação do Behaviorismo Radical como uma perspectiva determinista de compreensão do comportamento humano' (15 artigos), em contraste direto com a relação descrita acima de negação desta perspectiva. Liberdade humana (livre arbítrio), probabilidade, falta de conhecimento sobre todas as variáveis que participam da determinação do comportamento e suas interações e, conseqüentemente, capacidade de predição e controle do comportamento constituem o foco dos textos que afirmam que o Behaviorismo Radical é determinista. Estes temas não necessariamente aparecem conjuntamente em todos os artigos.

Além disso, alguns destes temas são abordados diferentemente por estes dois grupos de relações entre Behaviorismo Radical e determinismo, acima mencionados. Por exemplo, para os artigos agrupados como "negação do Behaviorismo Radical como perspectiva determinista de compreensão do comportamento humano", o conceito de probabilidade é utilizado como uma forma de oposição ao determinismo. Já para o conjunto de artigos classificados como 'afirmação do Behaviorismo Radical como uma perspectiva determinista de compreensão do comportamento humano' probabilidade não é entendida como um conceito que se opóe ao de determinismo. Aliás, de certa forma, estes dois conceitos são usados como complementares formando o conceito de "determinismo probabilístico". Neste sentido, a possibilidade de predição total e absoluta do fenômeno comportamental não seria uma característica fundamental do determinismo, como é possível observar no trecho abaixo:

Não há um único e simples determinante ("causa") para cada evento ("efeito") e sim vários 
possíveis determinantes para um mesmo evento. É o que marca a passagem de um determinismo absoluto ("há uma causa") para um determinismo apenas probabilístico (onde encontramos vários possíveis e atuais "eventos ou condiçōes" determinando o comportamento). Probabilístico é o tipo de determinismo que a ciência - e dentro dela a Análise Experimental do Comportamento - defende... (Botomé, 1982, p. 34)

Para os 15 artigos que afirmam o caráter determinista do Behaviorismo Radical (Figura 3), liberdade foi o tema mais freqüentemente abordado, presente em cinco artigos. Nestas análises o determinismo atribuído ao Behaviorismo Radical é discutido em contraste direto com a idéia de que o comportamento humano seja indeterminado, posição na qual o indivíduo teria uma "escolha livre", independente das diversas variáveis que influenciam o comportamento.

A afirmação de que o behaviorismo é uma filosofia determinista está presente desde a década de 70 até a década atual. Interessante notar que, embora tal afirmação tenha sempre estado presente, o número de artigos que fazem tal afirmação explicitamente (15) é pequeno em relação ao total de artigos que abordam a questão do determinismo (89). Isso pode evidenciar que tal afirmação parece ser consenso entre os autores que publicam sobre o tema, exceto para os que negam que o Behaviorismo Radical seja determinista. Mais que isto, houve uma diminuição (Figura 3, painel superior) na discussão que envolve respostas verbais de afirmar e negar o Behaviorismo Radical enquanto uma filosofia determinista, a partir de 2000. Na verdade, ao examinar a Figura 3, é possível constatar que há momentos em que tal discussão não ocorre (períodos sem publicação) com exceção do fim da década de 90 no qual houve uma concentração de publicações sobre estas relações.

Proximidade entre Behaviorismo Radical e modelos causais mecanicistas foi outra relação identificada. Modelos mecânicos são baseados na unidirecionalidade, linearidade e contigüidade espaço-temporal. A causa de um fenômeno, para estes modelos, é considerada como o evento imediatamente anterior ao fenômeno sob investigação. Afirmações ontológicas sobre aspectos do mundo que existem independentemente do organismo que interage com eles também são consideradas pelos autores como uma característica que aproxima o Behaviorismo Radical do mecanicismo.

Alguns destes artigos, ao discutirem o mecanicismo, fazem-no em relação ao contextualismo. Este tema foi abordado em 7 dos 11 artigos que compõem este grupo. Para os contextualistas, o comportamento é entendido como um fenômeno histórico e contextual, no qual as suas múltiplas variáveis controladoras interagem de inúmeras maneiras, a partir de uma história passada e de acordo com o contexto em vigor, na determinação do comportamento. Os diferentes autores, que abordam "contextualismo" ao aproximar Behaviorismo Radical de modelos mecânicos de causalidade, defendem que o Behaviorismo Radical apresenta características de modelos mecânicos, como a afirmação de uma realidade independente do sujeito que se comporta.

Vale notar que quase metade dos artigos deste grupo se concentra eminentemente em 1993 e que 10 dos 11 artigos foram publicadas entre 1992 e 1997, mostrando que a aproximação entre Behaviorismo Radical e modelos mecânicos de causalidade não tem sido 
proposta por quase 10 anos. Esta pausa relativamente longa de publicações que aproximam o Behaviorismo Radical do mecanicismo, juntamente com o pequeno número de artigos que propuseram tal relação (11 dos 89 artigos), pode servir de base para a afirmação de que é possível que tal relação esteja sendo superada pela comunidade de analistas do comportamento.

Outra relação identificada é de afastamento entre Behaviorismo Radical e modelos causais mecanicistas. Ao estabelecer tal relação, os autores recorrem a vários elementos para fundamentar suas afirmações, tais como: negação da noção de uma força (geralmente de caráter metafísico e, portanto, dualista), unidirecionalidade, linearidade e contigüidade espaço temporal entre as variáveis determinantes do comportamento e o próprio comportamento (elementos estes característicos de modelos mecânicos). Além disso, os autores deste grupo afirmam sua posição baseados em proposições sobre relação funcional, - referindo-se a um modelo que atenta para relações constantes e recíprocas (bidirecionais em oposição à unidirecionalidade) entre eventos - e sobre seleção por conseqüências/seleção natural referindo-se a um novo modelo causal que possui características diferentes dos modelos mecânicos, não requerendo seqüências lineares que servem de elos entre os eventos. Dos 41 artigos que compõem este grupo (Figura 3), 23 abordaram o tema seleção por conseqüências/ seleção natural e 18 abordaram o tema relação funcional para se oporem ao mecanicismo. Este dado revela que ambos os temas são freqüentemente mencionados ao se afastar o Behaviorismo Radical de modelos mecânicos.

Ao analisar a distribuição temporal dos artigos classificados neste grupo, observou-se a existência de apenas dois artigos na década de 80, 1982 e 1984, publicados logo depois do artigo Selection by Consequences de 1981. No entanto, é só na década de 90 que há uma grande freqüência de publicaçôes nas quais se identifica esta relação. $\mathrm{O}$ último artigo localizado que estabelece essa relação data de 2008. Portanto, é ainda atual a relação de afastamento entre Behaviorismo Radical e modelos mecânicos, diferentemente da relação anterior que os aproxima. Além disso, a quantidade de artigos nos quais foi identificada tal relação, quase metade do total de artigos, mostra sua importância.

O afastamento do Behaviorismo Radical de modelos de causalidade teleológicos ou finalistas foi mais uma relação identificada. Nesta relação entre Behaviorismo Radical e determinismo as causas do comportamento estariam no futuro, nas conseqüências futuras do comportamento, e não na história passada de condicionamento.

Dois temas aparecem regularmente neste grupo de artigos: "seleção por conseqüências/ seleção natural" e "mecanicismo". Dos oito artigos nos quais foi identificada esta relação, seis abordam estes dois temas. Como pode ser visto no trecho abaixo, a autora parece encontrar no modelo de 'seleção por conseqüências/ seleção natural' um contraponto ao modelo causal finalista:

O modelo de seleção por conseqüências permite a Skinner definitivamente resolver o problema da teleologia: é através deste modelo que se esclarece a aparente finalidade das mudanças comportamentais; é através dele que se esclarece que o ambiente opera como um selecionador e não como um indicador da direção a ser seguida por uma espécie, indivíduo, ou uma cultura. (Andery, 1997, p. 199) 
Por outro lado, parece que os autores não se baseiam no mecanicismo como um contra ponto ao modelo teleológico. A freqüência com que o tema mecanicismo aparece nos textos deste grupo parece estar relacionada com o fato de que, constantemente, este tema é abordado conjuntamente com o tema seleção por conseqüências/seleção natural (ver relação de afastamento entre Behaviorismo Radical e modelos causais mecanicistas).

Ao analisar este grupo de textos através dos anos foi possível observar que embora tenha havido publicações nas décadas de 70, 80 e na atual, é na década de 90 que elas se concentram (metade das publicações deste grupo). Este dado, juntamente com o baixo número de publicações que estabelecem essa relação (8 dos 89 artigos), indica que, assim como a aproximação do Behaviorismo Radical de modelos mecânicos de causalidade, a presente relação parece não ser uma variável que controle as análises da comunidade behaviorista radical

O modelo de determinação do Behaviorismo Radical como um modelo no qual as causas do comportamento estão em variáveis ambientais externas ao organismo que se comporta opõe-se a modelos de determinação que procuram as causas do comportamento em variáveis organísmicas (eventos privados e/ou estados mentais). A discussão gira em torno da natureza destes estímulos, de suas relaçôes funcionais com estímulos externos e do seu papel na determinação do comportamento. Os 14 artigos classificados neste grupo encontramse distribuídos desde a década de 70 até a década atual, sendo as últimas publicaçôes identificadas em 2006. Desta maneira, parece que discussões acerca do papel causal dos eventos privados nunca saíram de foco, constituindo-se ainda como discussão atual.
Todos os textos que alinham o Behaviorismo Radical com um modelo de determinação que afirma que o comportamento é resultado de diferentes níveis de determinação (ex.: filogenético, ontogenético e cultural) se baseiam no tema da seleção por conseqüências/ seleção natural.

Quando analisados através dos anos, verifica-se que os artigos deste grupo começaram a ser publicados em 1989, havendo uma aceleração do meio para o fim da década de 90. A última publicação encontrada foi de 2008. Estes dados revelam que respostas verbais que estabelecem esta relação são bem atuais. $\mathrm{O}$ relativo baixo número de publicações neste caso, 21 (cerca de 23\%) de um total de 89 artigos (ver Figura 3), pode não revelar acuradamente a importância desta relação, visto que a primeira publicação é datada de 1989, oito anos após a publicação do texto Seleção por conseqüências.

Além dessas, outras regularidades foram detectadas: alguns dos artigos nos quais foram encontradas respostas verbais de negar e de afirmar o determinismo relacionam sua posição com o afastamento ou aproximação do Behaviorismo Radical de modelos causais mecânicos. Geralmente, essa relação depende de como os autores definem determinismo. Do total de 12 textos que afirmam que o Behaviorismo Radical não é determinista oito o fazem no sentido de afastar o Behaviorismo Radical de modelos mecânicos de causalidade. Em outras palavras, negar o determinismo, nestes casos, é afastar o Behaviorismo Radical do mecanicismo e não postular que o fenômeno comportamental seja caprichoso ou indeterminado. Ainda há, neste grupo, outros dois textos que negam que o Behaviorismo Radical seja determinista, 
porém os autores deixam claro que esta é a posição deles e que tal posição é contrastante com a opinião de Skinner.

Dos 14 textos que apresentam definição de determinismo como relação funcional, nove textos relacionam o Behaviorismo Radical com modelos não mecânicos de causalidade. Outros três textos frisam que as causas do comportamento precisam ser buscadas em variáveis externas ao organismo que se comporta. Este dado mostra que relação funcional é uma característica utilizada pelos autores para afastar ou se opor a modelos causais mecanicistas. Além disso, este dado indica que ao afirmar um determinismo externalista os autores se fundamentam na relação funcional para descrever o papel causal das variáveis externas.

Dos 21 textos que definem determinismo como seleção por conseqüências, 13 ressaltam os diferentes níveis de determinação do comportamento, 11 afastam o Behaviorismo Radical de modelos mecanicistas e cinco afastam o Behaviorismo Radical de modelos teleológicos de determinação. A partir destes dados, fica claro que afirmar o modelo causal de seleção por conseqüências, bem como propor que o estabelecimento de relação funcional para descrever o comportamento, ocorre em afirmações que há uma oposição à possibilidade de relacionar Behaviorismo Radical e modelos mecanicistas de causalidade. Também fica claro que o modelo de seleção por conseqüências é utilizado para demonstrar que o comportamento é produto, não apenas de um nível de determinação, mas de diferentes níveis de determinação (filo, onto e cultural).

Alguns autores, ao discutirem determinismo e Behaviorismo Radical, analisam as respostas verbais de Skinner e deixam claro que não concordam com a posição de Skinner sobre o tema. Dentre os 89 artigos analisados, nove apresentam divergências explícitas entre o posicionamento dos autores e o de Skinner (como entendidas pelos autores dos textos). A partir do baixo número de divergências, parece plausível afirmar que as respostas verbais de Skinner sobre determinismo, enquanto um possível conjunto de variáveis controladoras das respostas verbais de outros autores, influenciaram o comportamento verbal da maioria dos autores de forma semelhante.

Em síntese, as análises realizadas indicam que a discussão sobre o tema deste trabalho perdura por mais de três décadas, embora o número de artigos publicados sobre o tema só tenha aumentado de freqüência a partir do fim da década de 80 .

$\mathrm{O}$ fato da maioria dos artigos apresentarem respostas verbais de considerar o Behaviorismo Radical como uma filosofia determinista (todas as respostas verbais encontradas, exceto as que explicitamente afastaram o determinismo do Behaviorismo Radical) está em concordância com as afirmações de Skinner $(1953,1947)$ e com a afirmação de Slife et al. (1999) de que o Behaviorismo Radical é considerado, de maneira geral, determinista.

Slife et al. (1999) também afirmaram que não há consenso sobre definição de determinismo na literatura behaviorista radical. As diferentes e, muitas vezes, divergentes definiçôes encontradas suportam tal afirmação.

A maioria dos artigos que nega que o Behaviorismo Radical seja uma filosofia determinista o faz, na verdade, no intuito de afastar o Behaviorismo Radical de noções mecânicas de causalidade. Essa conclusão é corroborada pelo fato de que mais da metade 
dos artigos que negam o determinismo apresenta definições que igualam determinismo e mecanicismo.

\section{REFERÊNCIAS}

Andery, M. A. P. A. (1997). O modelo de seleção por conseqüências e a subjetividade. Em R. A. Banaco (Org.), Sobre comportamento e cognição, Vol. 1, (pp.199-208). Santo André: ARBytes.

Baldwin, J. D. (1988). Mead and Skinner: Agency and Determinism. Behaviorism, 16, 109-127.

Begelman, D. A. (1978). Skinner's determinism. Behaviorism, 6, 13-25.

Bori, C. M. (2001). Fala de Dra. Carolina Bori, quando do recebimento do prêmio concedido pela $\mathrm{ABA}$ na sua reunião anual de 2001. Em H. J. Guilhardi, M. B. B. P. Guilhardi, M. B. B. P. Madi, P. B. Queiroz, \& M. C. Scoz, (Orgs.), Sobre Comportamento e Cognição, Vol. 7 (pp. 302-304). Santo André: ESETec.

Botomé, S. P. (1982). Determinação do comportamento e intervenção social: a contribuição da análise experimental do comportamento. Cadernos de Análise do Comportamento, 2, 30-68.

Chiesa, M. (1992). Radical Behaviorism and scientific frameworks: From mechanistic to relational accounts. American Psychologist, 47, 1287-1299.

Chiesa, M. (1994). Radical Behaviorism: the philosophy and the science. Boston: Authors Cooperative, Inc., Publishers.

Day, W. F. (1969). Radical Behaviorism in reconciliation with phenomenology. Journal of the Experimental Analysis of Behavior, 12, 315-328.

Fraley, L. E. (1994). Uncertainty about determinism: a critical review of challenges to the determinism of modern science. Behavior and Philosophy, 22, 7183.

Marr, J. (1982). Determinism. The Behavior Analyst, 5 , $205-207$.
Matos, M. A. (1996) Contingências para análise do comportamento no Brasil: Fred Keller. Psicologia: Teoria e Pesquisa, 12, 107-111.

Micheletto, N. (1997). Variação e Seleção: as novas possibilidades de compreensão do comportamento humano. Em R. A. Banaco (Org.), Sobre comportamento e cognição, Vol. 1 (pp.116-129). Santo André: ARBytes.

Morris, E. K. (1988). Contextualism: the world view of Behavior Analysis. Journal of the Experimental Child Psychology, 46, 289-323.

Moxley, R. A. (1997). Skinner: from determinism to random variation. Behavior and Philosophy, 25, 3-27.

Reese, H. W. (1993). Comments about Morris's Paper. The Behavior Analyst, 16, 67-74.

Scharif, J. L. (1982). Skinner's concept of the operant: From necessitarian to probabilistic causality. Behaviorism, 10, 45-54.

Skinner, B. F. (1999). Current Trends in Experimental Psychology. Em B. F. Skinner Cumulative Record. Acton, MA: Copley Publishing Group. (Obra original publicada em 1947)

Skinner, B. F. (1998). Ciência e comportamento humano (Trad. J. C. Todorov e R. Azzi). São Paulo: Martins Fontes. (Obra original publicada em 1953)

Skinner, B. F. (1992). Verbal Behavior. Acton, MA: Copley Publishing Group. (Obra original publicada em 1957)

Skinner, B. F. (1971). Beyond Freedom and Dignity. Indianapolis: Hackett Publishing Company, Inc.

Skinner, B. F. (1976). About Behaviorism. New York: Alfred A. Knopf. (Obra original publicada em 1974)

Skinner, B. F. (1987). Selection by consequences. Em B. F. Skinner. Upon Further Reflection. New Jersey: Prentice Hall, Inc. (Obra original publicada em 1981)

Skinner, B. F. (1989). Recent Issues in Analysis of Behavior. New Jersey: Prentice Hall Inc.

_Slife, B. D., Yanchar, S. C., \& Williams, B. (1999). 
Conceptions of determinism in radical behaviorism: A taxonomy. Behavior and Philosophy, 27, 75-96.

Tourinho, E. Z. (2003). A produção de conhecimento em psicologia: a análise do comportamento. Psicologia: Ciência e Profissão, 23, 30-41.

Vaughan Jr, W. (1983). Comments on Marr's determinism. The Behavior Analyst, 6, 111.

Vorsteg, R. H. (1974). Operant reinforcement theory and determinism. Behaviorism, 2, 108-119.

Submetido em 15 de dezembro de 2008 Aceito em 18 de junho de 2009 